\title{
ANALISIS LITERASI KEUANGAN SISWA SMK SELAMA PANDEMI COVID-19
}

\author{
Tsania Rahmawati ${ }^{1\}}$, Dudung Ma'ruf Nuris ${ }^{29}$ \\ ${ }^{1.2}$ Universitas Negeri Malang \\ tsaniar98 armail com
}

\begin{abstract}
The Coronavirus Disease (COVID-19) pandemic has resulted in economic turmoil that hit almost all countries in the world. In households that the econony affected due to the pandemic, the children who are still students also disadvantaged because of the implementation of online learning. With the economic downturn during pandemic, students from low-income family had lower opportunities in online learning than students from high-income family. This study aims to explain how is financial literacy of vocational students during COVID-19 pandemic. This study uses a qualitative approach and phenomenological study, with primary data consist of interview with one of the accounting teachers at SMKN I Malang. The data analysis was carried out in three stages: noema, noexis, and eidetic reduction, which were processed mamaally. Result of this study is that the application of financial literacy during pandemic has experienced limitations due to gaps in the facilities students have for online learning. The conclusion of this study is that financial literacy education isn't onty a task for educators to teach their students, but parents role is also important in the introduction of financial literacy. Financial literacy can be a provision for young generation in the future to move the wheels of economy which will have an impact on increasing national income and save the country from the impact of economic crisis due to the COVID-19 pandemic.
\end{abstract}

Keywords: Financial literacy; Finandial education; Vocational students; Pandemic; COVTD-19

\begin{abstract}
ABSTRAK
Pandemi Cononavirus Disease (COVID-19) mengakibatkan sejolak ckonomi yang melanda hampir seluruh negara di dunia. Dalam keluarga yang terdampak perckonomiannya akibat pandemi, anak yang masih berstatus sebagai pelajar juga dirugikan karena pelaksanaan kegiatan pembelajaran secara daring. Dengan menurunnya kondisi ekonomi selama masa pandemi, siswa yang berasal dari keluarga berekonomi rendah memiliki kesempatan belajar daring lebih rendah dibandingkan siswa yang berasal dari keluarga berekonomi tinggi. Penelitian ini bertujuan untuk menjelaskan bagaimana literasi keuangan siswa SMK selama pandemi COVID-19. Penelitian ini menggunakan pendekatan kualitatif dan studi fenomenologi, dengan data primer yang terdiri dari wawancara partisipan dengan salah satu guru akuntansi di SMKN 1 Malang. Analisis data melalui tiga tahapan yaitu noema. noesis, dan eidetic reduction yang diolah secara manual. Hasil dari penelitian ini adalah penerapan literasi keuangan pada masa pandemi mengalami keterbatasan dikarenakan adanya kesenjangan dalam fasilitas yang dimiliki siswa untuk pembelajaran daring. Kesimpulan dari penelitian ini adalah edukasi literasi keuangan tidak hanya menjadi tugas bagi para pendidik untuk mengajarkan kepada siswanya. tetapi peran orang tua juga sangat penting dalam pengenalan literasi keuangan. Literasi keuangan dapat menjadi bekal generasi muda di masa mendatang untuk menggerakkan roda perekonomian yang berdampak pada meningkatnya pendapatan negara, serta menyelamatkan negara dari dampak krisis ckonomi akibat pandemi COVID-19.
\end{abstract}

Kata Kunci: Literasi keuangan; Pendidikan keuangan; Siswa SMK; Pandemi; COVID-19 


\section{PENDAHULUAN}

Pandemi Coronavirus Disease (COVID-19) mengakibatkan gejolak ekonomi yang melanda hampir seluruh negara di dunia. Berbagai tindakan yang dilakukan untuk menekan jumlah penderita seperti work-at-home dan social distancing membuat kegiatan perekonomian menurun akibat berkurangnya aktivitas perekonomian masyarakat hingga menimbulkan pengurangan upah hingga pemecatan tenaga kerja. Bagi keluarga yang terdampak perekonomiannya akan kesulitan untuk memenuhi kebutuhan hidupnya, terutama bagi individual yang memiliki pengetahuan keuangan yang rendah. Seseorang yang 'melek' terhadap keuangannya atau memiliki literasi keuangan yang tinggi akan lebih siap menghadapi bencana atau kejadian tak terduga dengan memiliki dana darurat. Hasil penelitian terdahulu oleh Yuesti, dkk., (2020) menunjukkan bahwa individual yang memiliki sikap keuangan yang baik, dibuktikan dengan kemampuan pengelolaan keuangan yang baik mampu menyeimbangkan antara penghasilan dan pengeluarannya, serta mampu merencanakan dana darurat untuk masa depan. Sehingga ketika pandemi COVID-19 terjadi, masyarakat tidak terlalu stress dan mampu menyelamatkan keuangannya. Sebaliknya, kurangnya pengetahuan tentang keuangan akan meningkatkan stress dan ketidakpastian, sehingga mereka tidak punya kemampuan untuk membuat keputusan keuangan yang baik dan efektif (Chinen \& Endo, 2012).

Individu yang paling berisiko pada saat krisis ekonomi adalah anak-anak muda, wanita, dan orang-orang berpendidikan rendah (Preston, 2020). Penelitian oleh Cameron, dkk., (2014) yang menguji hubungan karakteristik demografi, karakter dan kemampuan siswa, sosialisasi konsumsi dan pengalaman keuangan, kekayaan orang tua, dan financial risk tolerance, menemukan bahwa tingkat literasi keuangan rendah terdapat pada siswa yang berasal dari keluarga kurang mampu, dan siswa yang memiliki kemampuan berbahasa inggris dan matematika yang rendah. Dalam keluarga yang terdampak perekonomiannya akibat pandemi, anak yang masih berstatus sebagai pelajar semakin dirugikan karena pelaksanaan kegiatan pembelajaran secara daring. Siswa harus memiliki gadget dan kuota internet agar bisa mengikuti kegiatan pembelajaran daring setiap harinya. Bagi siswa yang berasal dari keluarga yang kurang mampu, kebutuhan ini sangat sulit untuk terpenuhi, karena keluarga harus menambah biaya untuk membeli kuota internet yang tidak murah. Akibatnya, banyak siswa yang menurun semangat belajarnya.

Memahami literasi keuangan generasi muda sangat penting untuk membentuk program pendidikan keuangan yang efektif. Pendidikan literasi keuangan pada tingkat sekolah menengah adalah kunci untuk meningkatkan kemampuan pengambilan keputusan dalam keuangan pada masyarakat. Dengan adanya pandemi yang mengharuskan banyak kegiatan dilakukan secara online, tidak hanya belajar dan bekerja, tetapi berbelanja juga bisa dilakukan secara online. Meningkatnya aktivitas ekonomi secara online menggunakan electronic money juga memiliki pengaruh positif terhadap literasi keuangan, khususnya dalam situasi pandemi COVID-19 (Gusti, 2020). Siswa yang memiliki rekening bank sendiri cenderung memiliki literasi keuangan yang lebih tinggi dibandingkan yang tidak memilikinya (Mandell, 2008; Sohn, dkk., 2012). Dengan maraknya trend penggunaan electronic money seperti Go-Pay, $O V O$, dan beberapa aplikasi e-money lainnya yang mudah diakses bagi para generasi muda, yang tidak hanya berfungsi sebagai alat pembayaran, tetapi juga bisa digunakan untuk pembelian asuransi, produk investasi, penyimpanan uang, pinjaman online, dan sebagainya mampu meningkatkan pengetahuan keuangan dalam mengambil keputusan keuangannya. 
Pendidikan tentang literasi keuangan sangatlah penting bagi generasi muda yang akan menjadi agent of change. Adanya krisis ekonomi yang dialami selama pandemi juga mengajarkan bahwa pentingnya literasi keuangan sebagai bekal untuk hidup di masa depan yang semakin tidak menentu. Penelitian ini bertujuan untuk menjelaskan bagaimana literasi keuangan siswa SMK selama pandemi COVID-19.

\section{TINJAUAN PUSTAKA}

\section{Literasi Keuangan}

Literasi didefinisikan sebagai kemampuan seseorang individu untuk membaca, menulis, dan berbicara, menghitung dan memecahkan masalah pada tingkat kemahiran yang diperlukan, dalam individu, keluarga dan masyarakat (Remund, 2010). Huston (2010) mendefinisikan literasi keuangan menjadi dua dimensi, yaitu pengetahuan dan pengaplikasian. Dimensi pengetahuan yaitu memahami pengetahuan keuangan pribadi yang didapatkan dari kegiatan edukasi maupun pengalaman yang berhubungan dengan konsep dan produk keuangan, sedangkan dimensi aplikasi yaitu kemampuan untuk mempraktekkan atau menggunakan secara percaya diri dan efektif yang berhubungan dengan konsep dan produk keuangan.

Menurut Otoritas Jasa Keuangan (2017) yang dimaksud dengan literasi keuangan adalah serangkaian proses atau kegiatan untuk menambah pengetahuan, keterampilan, dan keyakinan yang mempengaruhi sikap dan perilaku keuangan untuk meningkatkan kualitas pengambilan keputusan dan pengelolaan keuangan dalam rangka mencapai kehidupan yang lebih baik. OJK membagi tingkat literasi keuangan penduduk Indonesia menjadi empat bagian yaitu sebagai berikut : 1) Well literate, yakni memiliki pengetahuan dan keyakinan tentang lembaga jasa keuangan serta produk jasa keuangan, termasuk fitur, manfaat dan risiko, hak dan kewajiban terkait produk dan jasa keuangan, serta memiliki keterampilan dalam menggunakan produk dan jasa keuangan, 2) Sufficient literate, memiliki pengetahuan dan keyakinan tentang lembaga jasa keuangan serta produk dan jasa keuangan, termasuk fitur, manfaat dan risiko, hak dan kewajiban terkait produk dan jasa keuangan, 3) Less literate, hanya memiliki pengetahuan tentang lembaga jasa keuangan, produk dan jasa keuangan, dan 4) Not literate, tidak memiliki pengetahuan dan keyakinan terhadap lembaga jasa keuangan serta produk dan jasa keuangan, serta tidak memiliki keterampilan dalam menggunakan produk dan jasa keuangan.

Literasi keuangan adalah proses dimana individual meningkatkan pemahaman mereka terhadap konsep dan produk keuangan, dan membentuk kemampuan dan percaya diri menjadi lebih sadar terhadap risiko dan kesempatan keuangan untuk mengambil keputusan untuk meningkatkan proteksi dan kesejahteraan diri (Atkinson \& Messy, 2012). Literasi keuangan bermanfaat agar masyarakat mampu mengambil keputusan dalam mengelola keuangan pribadinya secara optimal, yaitu dengan memilih produk dan jasa keuangan yang sesuai dengan kebutuhan, mengetahui manfaat dan risikonya, serta hak dan kewajiban sebagai konsumen keuangan. Semakin meningkatnya literasi keuangan masyarakat, diharapkan semakin banyak masyarakat yang menabung dan berinvestasi, dan berdampak semakin banyak masyarakat menggunakan produk dan layanan jasa keuangan yang pada akhirnya menjadi salah satu sumber pembiayaan pembangunan negara. 


\section{Pendidikan Literasi Keuangan}

Pada tahun 2008 OECD mendirikan International Network on Financial Education (INFE) sebagai wadah bagi para anggota untuk mendiskusikan perkembangan ekonomi terbaru di negara masing-masing serta membentuk studi analisis dan komparatif, metode, praktik, instrumen kebijakan dan tata cara praktik pada program pendidikan keuangan di sekolah. Fokus pendidikan keuangan adalah untuk generasi muda dan di lingkungan sekolah, dikarenakan perkembangan sistem dan produk keuangan yang semakin canggih saat ini generasi muda tidak mungkin bisa belajar dari generasi sebelumnya. Selain mempersiapkan generasi muda untuk kehidupan dewasa mereka, pendidikan keuangan di sekolah juga dapat mengatasi langsung masalah keuangan yang dihadapi generasi muda. Banyak anak-anak sekarang sudah menggunakan ponsel sehingga akses pada fasilitas pembayaran online sangat mudah, sehingga literasi keuangan akan bermanfaat bagi mereka saat menggunakan produk keuangan tersebut.

Di Indonesia salah satu upaya yang dilakukan OJK bersama dengan Direktorat Jenderal Pajak Kementerian Keuangan RI untuk mendorong literasi dan inklusi adalah dengan meluncurkan Buku Literasi Keuangan berbasis e-learning bagi para pelajar tingkat SD, SMP, SMA hingga perguruan tinggi. Cakupan materi dalam buku tersebut antara lain adalah pengenalan OJK, Perbankan, Pasar Modal dan Industri Keuangan Non Bank (termasuk Perasuransian, Lembaga Pembiayaan, Dana Pensiun, dan Pergadaian).

\section{Pendidikan Selama Pandemi COVID-19}

Sebagai upaya untuk menekan penyebaran pandemi di Indonesia, pemerintah menutup lembaga pendidikan dan menyelenggarakan belajar di rumah secara online atau daring bagi para siswa. Hal ini memberikan dampak yang besar bagi dunia pendidikan karena berbagai keterbatasan yang ada, seperti penguasaan teknologi, sarana yang kurang memadai, akses internet yang terbatas, dan kurang siapnya penyediaan anggaran untuk kebutuhan pembelajaran daring (Aji, 2020). Keterbatasan tersebut menyebabkan penurunan semangat belajar siswa karena mereka tidak bisa mengakses kegiatan pembelajaran dengan mudah. Bagi siswa yang tidak memiliki gadget dan akses internet yang lancar, kegiatan belajar daring akan sulit sekali untuk dilakukan. Berbagai bantuan diturunkan agar kegiatan belajar di Indonesia masih bisa berjalan dengan pemberian kuota internet gratis bagi guru dan siswa, hingga ada kasus dimana guru dengan sukarela mendatangi rumah siswa yang tidak memiliki gadget agar siswanya masih bisa mengikuti proses pembelajaran.

\section{METODOLOGI PENELITIAN}

Penelitian ini menggungakan pendekatan kualitatif dengan jenis penelitian studi fenomenologi, yaitu menggali informasi dengan terjun ke lapangan dan melakukan interaksi langsung dengan subjek yang diteliti untuk mengungkapkan serta memahami fenomena yang dialami siswa akuntansi di SMKN 1 Malang selama masa pandemi. Dikarenakan pandemi sedang berlangsung sehingga tidak memungkinkan untuk terjun dan interaksi secara langsung, pengambilan data dilakukan dengan wawancara kepada salah satu guru akuntansi di SMKN 1 Malang. 


\section{HASIL DAN PEMBAHASAN}

SMKN 1 Malang merupakan salah satu sekolah menengah kejuruan di Kota Malang yang mementingkan literasi keuangan siswanya. Literasi keuangan sudah dikenalkan sejak Masa Pengenalan Lingkungan Sekolah (MPLS) juga sering disampaikan tiap kegiatan upacara pada hari Senin oleh pembina upacara dan tiap bimbingan oleh wali kelas dengan memotivasi siswa tentang pengelolaan keuangan, pentingnya menabung, dan kegiatan berwirausaha. SMKN 1 Malang memiliki fasilitas Bank Mini yang bisa diakses seluruh warga sekolah. Setiap siswa wajib memiliki rekening tabungan. Temuan ini mendukung penelitian sebelumnya oleh Widyastuti, dkk., (2016) yang menyatakan bahwa literasi keuangan memiliki pengaruh terhadap perilaku menabung. Bank Mini tidak hanya melayani tabungan tetapi bisa melayani pembayaran listrik, telepon, dan air bagi warga sekolah, orang tua siswa, serta warga sekitar yang membutuhkan. Bank Mini juga tersedia untuk menunjang kegiatan siswa di kelas yaitu praktek pelajaran akuntansi perbankan dan kegiatan magang, setiap harinya terdapat siswa yang ditugasi untuk menjadi pegawai dan melayani nasabah yang datang.

Meskipun tidak ada pelajaran khusus yang mengajarkan materi tabungan, investasi, dan pasar modal, materi tersebut telah dikenalkan dalam mata pelajaran akuntansi keuangan. Materi pasar modal akan ditambahkan secara mendalam bagi siswa yang mau mengikuti lomba di luar kegiatan kelas. Khusus dalam kompetensi akuntansi hanya diajarkan materi akuntansi perbankan secara umum. Kemampuan siswa akuntansi dalam menyusun laporan keuangan berbeda setiap tingkatan kelas. Kemampuan siswa kelas 10 masih bisa dikatakan belum pandai karena mereka masih dalam tahap pengenalan, tetapi sudah bisa dikatakan mampu dalam menyusun laporan keuangan perusahaan jasa sederhana. Kompetensi dalam menyusun laporan keuangan baru bisa terlihat nyata ketika siswa sudah mengikuti LSP.

Dengan adanya pandemi yang mengharuskan seluruh siswa melakukan kegiatan pembelajaran secara daring sejak semester gasal tahun ajaran 2019-2020, kegiatan pemberian materi dilakukan dengan memberikan materi dalam bentuk audiovisual berupa powerpoint dengan suara penjelasan dari guru yang bisa didownload dan dibuka kapan saja lewat $e$ learning. Hal tersebut dinilai lebih menghemat waktu, tenaga, dan biaya daripada harus menjelaskan materi melalui media interaksi langsung seperti zoom atau google meet, namun penggunaan goole meet sewaktu-waktu masih dilakukan hanya bagi siswa yang berkenan dan hanya dalam waktu singkat, karena pihak sekolah mempertimbangkan kuota internet yang dimiliki oleh siswa. Meskipun kegiatan pembelajaran berjalan setiap harinya, terdapat beberapa siswa yang memiliki keterbatasan sehingga tidak bisa mengikuti pembelajaran daring secara maksimal, terutama banyak siswa SMK yang berdomisili di luar Kota Malang dan berasal dari keluarga yang kurang mampu, seringkali mereka yang tidak memiliki gadget harus menunggu ayah atau kakak pulang kerja untuk meminjam gadget nya agar bisa belajar. Untuk melayani siswa yang hanya bisa online di malam hari, guru juga membuka layanan untuk bertanya lewat whatsapp selama 24 jam.

Sikap dan perilaku yang baik dalam menghadapi kondisi pandemi saat ini dikarenakan pengetahuan masyarakat yang baik tentang pengelolaan keuangan keluarga dan pencegahan penurunan ekonomi akibat pandemi COVID-19. Literasi yang baik bisa didapatkan dari lingkungan keluarga, lingkungan pendidikan formal, dan lingkungan sekitarnya. Pada 
lingkungan keluarga, orang tua memegang peran penting dalam mendidik anak untuk mengelola keuangannya sejak dini dan memberikan contoh pengambilan keputusan keuangan yang baik. Literasi keuangan yang baik akan menciptakan kesejahteraan keuangan, termasuk ketika pandemi terjadi.

\section{PENUTUP}

Membekali generasi muda dengan pendidikan keuangan sangat penting untuk meratakan literasi keuangan akibat perbedaan status sosial ekonomi siswa, dan berpotensi menurunkan kesenjangan ekonomi di masa depan. Latar belakang sosial ekonomi siswa memiliki pengaruh terhadap kinerja dan prestasi siswa pada kegiatan pembelajaran selama masa pandemi. Dengan menurunnya kondisi ekonomi selama masa pandemi, siswa yang berasal dari keluarga berekonomi rendah memiliki kesempatan belajar daring lebih rendah dibandingkan siswa yang berasal dari keluarga berekonomi tinggi, sehingga mereka perlu mendapatkan bantuan ekonomi dan dorongan dari pihak sekolah dan guru agar mereka tetap bisa melanjutkan kegiatan pembelajaran.

Edukasi mengenai literasi keuangan dapat dimulai dari lingkungan sekolah. Sekolah berperan penting dalam mengedukasi siswanya mengenai pentingnya memiliki tabungan, asuransi, mengetahui kegunaan pasar modal, serta mengenalkan produk-produk dan layanan jasa keuangan agar di masa depan ketika mereka terjun ke dunia kerja yang sesungguhnya dan diharuskan untuk mengambil keputusan keuangannya sendiri, mereka tidak akan kebingungan dan dapat mengambil keputusan secara bijak. Dengan tingginya tingkat literasi keuangan juga mampu menggerakkan roda perekonomian yang berdampak pada meningkatnya pendapatan negara, serta menyelamatkan negara dari dampak krisis ekonomi akibat pandemi COVID-19.

\section{DAFTAR RUJUKAN}

Aji, R. H. (2020). Dampak Covid-19 pada Pendidikan di Indonesia: Sekolah, Keterampilan, dan Proses Pembelajaran. Jurnal Sosial \& Budaya SYAR-I, 7(5), 395-402. doi:http://dx.doi.org/10.15408/sjsbs.v7i5.15314

Atkinson, A., \& Messy, F.-A. (2012). Measuring Financial Literacy: Results of the OECD / International Network on Financial Education (INFE) Pilot Study. OECD Working Papers on Finance, Insurance and Private Pensions, 15. doi:10.1787/5k9csfs90fr4-en

Cameron, M. P., Calderwood, R., Cox, A., Lim, S., \& Yamaoka, M. (2014). Factors associated with financial literacy among high school students in New Zealand. International Review of Economics Education, 16, 12-21. doi:10.1016/j.iree.2014.07.006

Chinen, K., \& Endo, H. (2012). Effects of Attitude and Background on Personal Financial Ability: A Student Survey in the United States. International Journal and Management, 29(1), 33-45. Diambil kembali dari https://search.proquest.com/openview/8cb3e4b31d21caeaaad415c4d62d5431/1?pqorigsite $=$ gscholar\&cbl $=5703$ 
Gusti, G. P. (2020). Is There Any Impact of Electronic Money to Increase Knowledge of Financial Literacy?: In the Pandemic Situation of Covid-19 in Pontianak City. Malaysian E Commerce Journal, 48-53. doi:10.26480/mecj.02.2020.48.53

Huston, S. J. (2010). Measuring Financial Literacy. The Journal of Consumer Affairs, 44(2), 296-316.

Mandell, L. (2008). The Financial Literacy of Young American Adults: Results of the 2008 National Jump\$Tart Coalition Survey of High School Seniors and College Students. The Jump\$tart Coalition for Personal Financial Literacy. Diambil kembali dari http://views.smgww.org/assets/pdf/2008\%20JumpStart\%20Financial\%20Literacy\%20 Survey.pdf

Preston, A. (2020). COVID-19: COVID-19 and The Importance of Financial Literacy. The University of Western Australia. Diambil kembali dari https://www.news.uwa.edu.au/2020042812027/uwa-public-policy-institute/covid-19covid-19-and-importance-financial-literacy?page=show

Remund, D. L. (2010). Financial Literacy Explicated: The Case for a Clearer Definition in an Increasingly Complex Economy. The Journal of Counsumer Affairs, 44(2), 275-295. doi:10.1111/j.1745-6606.2010.01169.x

Sohn, S., Joo, S., Grable, J. E., Lee, S., \& Kim, M. (2012). Adolescents' financial literacy: The role of financial socialization agents, financial experience, and money attitudes in shaping financial literacy among South Korean youth. Journal of Adolescence, 1-12. doi:10.1016/j.adolescence.2012.02.002

Widyastuti, U., Suhud, U., \& Sumiati, A. (2016). The Impact of Financial Literacy on Student Teachers' Saving Intention and Saving Behaviour. Mediterranean Journal of Social Sciences, 7(6). doi:10.5901/mjss.2016.v7n6p41

Yuesti, A., Rustiarini, N. W., \& Suryandari, N. N. (2020). Financial Literacy in The Covid19 Pandemic: Pressure Conditions in Indonesia. Enterpreneurship and Sustainability Issue, 8(1), 884-898. doi:10.9770/jesi.2020.8.1(59) 